\title{
Influence of Lifestyles on Mild Cognitive Impairment: A Decision Tree Model Study
}

This article was published in the following Dove Press journal:

Clinical Interventions in Aging

\author{
Zongqiu Wang $\mathbb{D}^{1, *}$ \\ Jiwen $\mathrm{Hou}^{2, *}$ \\ Yu Shi ${ }^{3}$ \\ Qiaowen Tan (D) ${ }^{\prime}$ \\ Lin Peng' \\ Zhiying Deng' \\ Zhihong Wang' \\ Zongjun Guo'
}

'Department of Geriatrics, The Affiliated Hospital of Qingdao University, Qingdao, People's Republic of China; ${ }^{2}$ Department of Geriatrics, The Affiliated Hospital of Chengdu University, Chengdu, People's Republic of China; ${ }^{3}$ Department of Critical Medicine, Weihai Central Hospital, Weihai, People's Republic of China

*These authors contributed equally to this work
Correspondence: Zongjun Guo Department of Geriatrics, The Affiliated Hospital of Qingdao University, No. 16 Jiangsu Road, Qingdao, Shandong 266003, People's Republic of China Email guozjj@I63.com
Objective: To explore the effects of different lifestyle choices on mild cognitive impairment (MCI) and to establish a decision tree model to analyse their predictive significance on the incidence of MCI.

Methods: Study participants were recruited from geriatric and physical examination centres from October 2015 to October 2019: 330 MCI patients and 295 normal cognitive (NC) patients. Cognitive function was evaluated by the Mini-Mental State Examination Scale (MMSE) and Clinical Dementia Scale (CDR), while the Barthel Index (BI) was used to evaluate life ability. Statistical analysis included the $\chi^{2}$ test, logistic regression, and decision tree. The ROC curve was drawn to evaluate the predictive ability of the decision tree model. Results: Logistic regression analysis showed that low education, living alone, smoking, and a high-fat diet were risk factors for MCI, while young age, tea drinking, afternoon naps, social engagement, and hobbies were protective factors for MCI. Social engagement, a highfat diet, hobbies, living condition, tea drinking, and smoking entered all nodes of the decision tree model, with social engagement as the root node variable. The importance of predictive variables in the decision tree model showed social engagement, a high-fat diet, tea drinking, hobbies, living condition, and smoking as $33.57 \%, 27.74 \%, 22.14 \%, 11.94 \%, 4.61 \%$, and $0 \%$, respectively. The area under the ROC curve predicted by the decision tree model was 0.827 (95\% CI: 0.795 0.856).

Conclusion: The decision tree model has good predictive ability. MCI was closely related to lifestyle; social engagement was the most important factor in predicting the occurrence of MCI.

Keywords: lifestyle, behaviours habit, mild cognitive impairment, influencing factors, decision tree model

\section{Introduction}

Mild cognitive impairment (MCI) is a common age-related cognitive disorder that is a transitional stage between normal aging and dementia. ${ }^{1}$ According to Petersen's survey in $2018,{ }^{2}$ the prevalence rate of MCI in people aged 60 to 64 years in the United States was $6.7 \%$. For those over 80 years, the prevalence rate of MCI reached $25.2 \%$, and the cumulative incidence of dementia in those with MCI older than 65 years after a follow-up for two years was $14.9 \%$. Therefore, MCI is considered to be the precursory stage of dementia; early identification of and intervention with the factors affecting the occurrence and development of MCI may play an important role in its prevention.,

A decision tree is a simple and powerful machine learning model that utilises any information obtained to find the best classification index of data samples. These 
classification indexes are the nodes of the decision tree, which then grow to form the tree structure. ${ }^{5}$ At present, the decision tree model has been successfully applied to research on public health and health behaviour. ${ }^{6}$ Not only can it determine the influencing factors of a disease and reflect the interaction among them, ${ }^{7,8}$ but it can also be used to predict the disease. ${ }^{9-12}$ Therefore, a variety of factors affecting MCI can be comprehensively analysed. Previous studies have found that lifestyle (such as drinking habits, smoking, and exercise), age, and educational attainment are related to the occurrence of MCI. ${ }^{13-15}$ However, there are relatively few studies on the interaction of different influencing factors on MCI. Therefore, this study aimed, through the decision tree method, to produce a model that predicts the interactions of the influencing factors and MCI in order to intervene with or delay its occurrence and development.

\section{Methods}

\section{Research Object}

The inclusion criteria of the MCI group were as follows: age $\geq 60$ years old and meets the core clinical criteria of MCI (i.e. cognitive problems, at least one cognitive impairment, independence of daily function, and absence of dementia). ${ }^{16}$ The inclusion criteria of the normal cognitive (NC) group were as follows: age $\geq 60$ years old, no symptoms or signs of cognitive decline or impairment were found during physical examination, and the two evaluation tools for cognitive function were normal. The exclusion criteria included presence of other important neurological diseases other than MCI (such as Parkinson's disease, epilepsy, and cerebral infarction); ${ }^{17}$ presence of clinically advanced or unstable diseases (such as advanced tumours and severe infections); a history of schizophrenia, mania, or depression; ${ }^{18}$ and the inability to cooperate with the completion of the questionnaire. From October 2015 to October 2019, 625 cases in geriatric and physical examination centres met the above criteria and were collected: 330 cases in the MCI group and 295 cases in the NC group. All patients were informed of the purpose of this study and provided consent. For patients with obvious cognitive impairment, we have obtained the consent of their families. The informed verbal consent process was approved by the Medical Ethics Committee of the Affiliated Hospital of Qingdao University (QYFYWZLL25697) and complied with the Declaration of Helsinki.

\section{Introduction of Evaluation Scale Mini-Mental State Examination (MMSE)}

The MMSE scale consists of 30 questions relating to orientation, memory, attention, reading construction, and comprehension with a total possible score of 30 points. According to the level of education, the criteria for judging cognitive impairment are as follows: illiteracy group $\leq 19$ points, primary school group $\leq 22$ points, and junior high school and above group $\leq 26$ points. MMSE is one of the methods to judge whether the cognitive function is normal or not and can not replace the clinical diagnosis. In addition, it contributes to the earle detecion of dementia patients and reduces missed diagnosis. ${ }^{19}$

\section{Clinical Dementia Rating Scale (CDR)}

CDR scores were obtained by questioning patients and people with close relationships with them (such as family members and caregivers) and assessing each of the six cognitive categories (memory, orientation, judgment and problem solving, community affairs, family and hobbies, and personal care). The scoring standard was five points, no dementia $=0$, suspected dementia $=0.5$, mild dementia $=1$, moderate dementia $=2$, and severe dementia $=3 .^{20} \mathrm{In}$ this study, this scale was used to distinguish mild cognitive impairment from dementia.

\section{Ability of Daily Living Assessment}

In this study, the widely used Barthel Index (BI) scale was adopted to evaluate the activities of daily living (ADL), which mainly include eating, bathing, grooming, dressing, controlling defecation, controlling urination, going to the toilet, bed and chair transfer, walking on the ground for 45 minutes, and walking up and downstairs, with a total possible score of 100 points. The higher the score, the better the independence. Based on the total possible score, ADL was divided into the following ranges: 100 points for normal activities of daily living, 60 points for good and basic self-care, 59-40 points for moderate dysfunction and need of help, 39-20 points for severe dysfunction and life dependence, and below 20 points for complete disability and complete life dependence. ${ }^{21}$ This study followed the diagnostic criteria of $\mathrm{MCI}$, with $\mathrm{BI}$ index $\geq 60$ points, indicating independence of daily life.

\section{Research methods}

The researchers used standardised language and unified scale score standards to obtain medical history and 
Table I MCI Studies Variable Assignment

\begin{tabular}{|c|c|}
\hline $\begin{array}{l}\text { Research } \\
\text { Variables }\end{array}$ & Assignment Situation \\
\hline Cognitive state & $\mathrm{MCl}=\mathrm{I}, \mathrm{NC}=2$ \\
\hline Gender & Male $=1$, female $=2$ \\
\hline Age group (years) & $60-64=1,65-69=2,70-74=3,75-79=4, \geq 80=5$ \\
\hline Educational level & $\begin{array}{l}\text { Illiteracy }=I \text {, primary school }=2 \text {, middle school } \\
=3 \text {, high school }=4 \text {, university }=5\end{array}$ \\
\hline Occupation & Mental labour $=\mathrm{I}$, physical labour $=2$ \\
\hline Living condition & Live alone $=1$, live with family $=2$ \\
\hline Drinking & Yes $=1, \mathrm{no}=2$ \\
\hline Smoking & Yes $=1$, no $=2$ \\
\hline Drink tea & Yes $=1$, no $=2$ \\
\hline Sleep time (hours) & $<7=1,7-9=2,>9=3$ \\
\hline Nap & Yes $=1$, no $=2$ \\
\hline Physical exercise & Yes $=1$, no $=2$ \\
\hline Social engagement & Yes $=1$, no $=2$ \\
\hline Hobbies & Yes $=1$, no $=2$ \\
\hline High-fat diet & Yes $=1$, no $=2$ \\
\hline
\end{tabular}

perform a physical examination, using MMSE, CDR, and ADL evaluation and collecting demographic, lifestyle and behaviour habits, and other data. The data were then double-checked to ensure accuracy and assign values to the research variables (Table 1).

\section{Statistical Analysis}

The data were analysed using IBM SPSS 25.0 software. $\chi^{2}$ test was used for single-factor analysis, binary logistic regression analysis was used to analyse the influencing factors, and $P<0.05$ was considered statistically significant. The decision tree model was established by using IBM SPSS Modeler 14.1 software decision tree C5.0 algorithm; MedCalc 15.2.2 software was used to draw the ROC curve.

\section{Results}

\section{Characteristics of General Demographic Data}

This study enrolled 625 elderly people classified either in the MCI group (330 cases) or the NC group (295 cases). There were 301 males and 324 females. The constituent ratio of those in $\mathrm{MCI}$ group relative to their counterparts in the NC group was as follows: according to sex, $55 \%$ male and 51\% female; according to age, 41\% 60-64 years old, 52\% 65-69 years, 57\% 70-74 years, $68 \%$ $75-79$ years, and $62 \%$ over 80 years; according to educational attainment, $61 \%$ illiterate, 59\% primary school,
$50 \%$ junior high school, $51 \%$ senior high school, and $12 \%$ above college; according to occupation, $51 \%$ mental work and 54\% manual work; and according to living situation, $84 \%$ living alone and $48 \%$ living with family (Table 2).

\section{Single Factor Analysis on the Influence of Lifestyle on $\mathrm{MCl}$}

There were significant differences $(P<0.005)$ between the $\mathrm{MCI}$ and NC groups in all of the following aspects: age $(P<0.0001)$, educational attainment $(P<0.0001)$, living condition $(P<0.0001)$, smoking habits $(P=0.016)$, tea drinkers $(P<0.0001)$, afternoon naps $(P<0.0001)$, physical exercise $(P<0.0001)$, social engagement $(P<0.0001)$, hobbies $(P<0.0001)$, and a high-fat diet $(P<0.0001)$. Among them, the proportion of participants with MCI was lower with regard to young age, tea drinking, afternoon naps, physical exercise, social engagement, and hobbies. The elderly with a low level of education, who lived alone, who smoked, or who had a high-fat diet had a higher proportion of MCI (Table 2).

\section{Binary Logistic Regression Analysis on the Influence of Lifestyle on $\mathrm{MCl}$}

Taking MCI as the dependent variable and the statistically significant factors in the single factor analysis as independent variables, binary logistic regression analysis showed that age, education, living condition, smoking habits, tea drinking, afternoon naps, social engagement, hobbies, and a high-fat diet were the influencing factors of MCI. Among them, illiteracy ( $\mathrm{OR}=12.248$, 95\% CI: 3.088 48.571), an educational attainment of primary school (OR=8.975, 95\% CI: 2.482-32.452), junior high school $(\mathrm{OR}=6.445,95 \%$ CI: $1.749-23.743)$, or senior high school $(\mathrm{OR}=6.386,95 \%$ CI: $1.640 \mathrm{mi}$ 24.873), living alone $(\mathrm{OR}=5.026, \quad 95 \% \quad \mathrm{CI}: \quad 2.204-11.463), \quad$ smoking $(\mathrm{OR}=2.702,95 \% \mathrm{CI}: 1.674-4.362)$, and a high-fat diet $(\mathrm{OR}=2.955,95 \% \mathrm{CI}: 1.892-4.615)$ were risk factors for the occurrence of MCI. However, being in the age range of 60-64 years $(\mathrm{OR}=0.23,95 \% \mathrm{CI}: 0.096-0.572)$ or $65-69$ years $(\mathrm{OR}=0.309,95 \% \mathrm{CI}: 0.127-0.754)$, drinking tea $(\mathrm{OR}=0.285,95 \% \mathrm{CI}: 0.182-0.447)$, taking afternoon naps ( $\mathrm{OR}=0.566,95 \% \mathrm{CI}: 0.350-0.916)$, taking part in social engagement (OR $=0.145,95 \%$ CI: $0.091-0.233)$, and having hobbies (OR $=0.421,95 \%$ CI: $0.264-0.671)$ were the protective factors for the occurrence of MCI (Table 3). 
Table 2 Single Factor Analysis of the Influence of Lifestyle on $\mathrm{MCl}$

\begin{tabular}{|c|c|c|c|c|c|c|c|}
\hline Research Variables & Category & NC & $\mathrm{MCl}$ & Total & MCI Constituent Ratio (\%) & $\chi^{2}$ & $P$ \\
\hline Gender & $\begin{array}{l}\text { Male } \\
\text { Female }\end{array}$ & $\begin{array}{l}137 \\
158\end{array}$ & $\begin{array}{l}164 \\
166\end{array}$ & $\begin{array}{l}301 \\
324\end{array}$ & $\begin{array}{l}55 \\
51\end{array}$ & 0.662 & 0.416 \\
\hline Age group (years) & $\begin{array}{l}60-64 \\
65-69 \\
70-74 \\
75-79 \\
\geq 80\end{array}$ & $\begin{array}{l}112 \\
78 \\
57 \\
28 \\
20\end{array}$ & $\begin{array}{l}79 \\
83 \\
76 \\
60 \\
32\end{array}$ & $\begin{array}{l}191 \\
161 \\
133 \\
88 \\
52\end{array}$ & $\begin{array}{l}41 \\
52 \\
57 \\
68 \\
62\end{array}$ & 21.083 & $<0.001$ \\
\hline Educational level & $\begin{array}{l}\text { Illiteracy } \\
\text { Primary school } \\
\text { Middle school } \\
\text { High school } \\
\text { University }\end{array}$ & $\begin{array}{l}27 \\
115 \\
69 \\
48 \\
36\end{array}$ & $\begin{array}{l}43 \\
163 \\
70 \\
49 \\
5\end{array}$ & $\begin{array}{l}70 \\
278 \\
139 \\
97 \\
41\end{array}$ & $\begin{array}{l}61 \\
59 \\
50 \\
51 \\
12\end{array}$ & 33.547 & $<0.001$ \\
\hline Occupation & $\begin{array}{l}\text { Mental labour } \\
\text { Physical labour }\end{array}$ & $\begin{array}{l}121 \\
174\end{array}$ & $\begin{array}{l}127 \\
203\end{array}$ & $\begin{array}{l}248 \\
377\end{array}$ & $\begin{array}{l}51 \\
54\end{array}$ & 0.417 & 0.518 \\
\hline Living condition & $\begin{array}{l}\text { Live alone } \\
\text { Live with family }\end{array}$ & $\begin{array}{l}13 \\
282\end{array}$ & $\begin{array}{l}68 \\
262\end{array}$ & $\begin{array}{l}81 \\
544\end{array}$ & $\begin{array}{l}84 \\
48\end{array}$ & 36.235 & $<0.001$ \\
\hline Drinking & $\begin{array}{l}\text { Yes } \\
\text { No }\end{array}$ & $\begin{array}{l}94 \\
201\end{array}$ & $\begin{array}{l}97 \\
233\end{array}$ & $\begin{array}{l}191 \\
434\end{array}$ & $\begin{array}{l}51 \\
54\end{array}$ & 0.443 & 0.508 \\
\hline Smoking & $\begin{array}{l}\text { Yes } \\
\text { No }\end{array}$ & $\begin{array}{l}79 \\
216\end{array}$ & $\begin{array}{l}118 \\
212\end{array}$ & $\begin{array}{l}197 \\
428\end{array}$ & $\begin{array}{l}60 \\
50\end{array}$ & 5.816 & 0.016 \\
\hline Drink tea & $\begin{array}{l}\text { Yes } \\
\text { No }\end{array}$ & $\begin{array}{l}213 \\
82\end{array}$ & $\begin{array}{l}117 \\
213\end{array}$ & $\begin{array}{l}330 \\
295\end{array}$ & $\begin{array}{l}35 \\
72\end{array}$ & 84.405 & $<0.001$ \\
\hline Sleep time (hours) & $\begin{array}{l}<7 \mathrm{~h} \\
7-9 \mathrm{~h} \\
>9 \mathrm{~h}\end{array}$ & $\begin{array}{l}154 \\
123 \\
18\end{array}$ & $\begin{array}{l}175 \\
138 \\
17\end{array}$ & $\begin{array}{l}329 \\
261 \\
35\end{array}$ & $\begin{array}{l}53 \\
53 \\
49\end{array}$ & 0.272 & 0.873 \\
\hline Nap & $\begin{array}{l}\text { Yes } \\
\text { No }\end{array}$ & $\begin{array}{l}215 \\
80\end{array}$ & $\begin{array}{l}194 \\
136\end{array}$ & $\begin{array}{l}409 \\
216\end{array}$ & $\begin{array}{l}47 \\
63\end{array}$ & 13.680 & $<0.001$ \\
\hline Physical exercise & $\begin{array}{l}\text { Yes } \\
\text { No }\end{array}$ & $\begin{array}{l}213 \\
82\end{array}$ & $\begin{array}{l}170 \\
160\end{array}$ & $\begin{array}{l}383 \\
242\end{array}$ & $\begin{array}{l}44 \\
66\end{array}$ & 28.096 & $<0.001$ \\
\hline Social engagement & $\begin{array}{l}\text { Yes } \\
\text { No }\end{array}$ & $\begin{array}{l}178 \\
117\end{array}$ & $\begin{array}{l}74 \\
256\end{array}$ & $\begin{array}{l}252 \\
373\end{array}$ & $\begin{array}{l}29 \\
69\end{array}$ & 93.051 & $<0.001$ \\
\hline Hobbies & $\begin{array}{l}\text { Yes } \\
\text { No }\end{array}$ & $\begin{array}{l}240 \\
55\end{array}$ & $\begin{array}{l}164 \\
166\end{array}$ & $\begin{array}{l}404 \\
221\end{array}$ & $\begin{array}{l}41 \\
75\end{array}$ & 68.302 & $<0.001$ \\
\hline High-fat diet & $\begin{array}{l}\text { Yes } \\
\text { No }\end{array}$ & $\begin{array}{l}101 \\
194\end{array}$ & $\begin{array}{l}236 \\
94\end{array}$ & $\begin{array}{l}337 \\
288\end{array}$ & $\begin{array}{l}70 \\
33\end{array}$ & 87.116 & $<0.001$ \\
\hline
\end{tabular}

Decision Tree Model of the Influence of Lifestyle on $\mathrm{MCl}$

The statistically significant factors in the univariate analysis were selected for the decision tree analysis. Selecting social engagement, a high-fat diet, hobbies, living condition, tea drinking, and smoking habits as each node of the decision tree model and social engagement as the root node variable, the results showed that the probability of $\mathrm{MCI}$ in people who had social engagement was $29.365 \%$ (74 cases), lower than those without social engagement (68.633\%; 256 cases). Among the participants who had social engagement, the probability of MCI among people with a high-fat diet was $53.782 \%$ (64 cases), higher than that of those with a non- 
Table 3 Binary Logistic Regression Analysis of the Influence of Lifestyle on $\mathrm{MCl}$

\begin{tabular}{|l|l|l|l|l|}
\hline Research Variables & $\boldsymbol{\beta}$ & Walds & $\boldsymbol{P}$ & OR (95\% Cl) \\
\hline $60-64$ years & -1.450 & 10.184 & 0.001 & $0.235(0.096-0.572)$ \\
$65-69$ years & -1.174 & 6.653 & 0.010 & $0.309(0.127-0.754)$ \\
$70-74$ years & $-0.75 I$ & 2.647 & 0.104 & $0.472(0.191-1.166)$ \\
$75-79$ years & -0.092 & 0.034 & 0.854 & $0.912(0.343-2.428)$ \\
Illiteracy & 2.505 & 12.704 & 0.000 & $12.248(3.088-48.571)$ \\
Primary school & 2.194 & 11.199 & 0.001 & $8.975(2.482-32.452)$ \\
Middle school & 1.863 & 7.843 & 0.005 & $6.445(1.749-23.743)$ \\
High school & 1.854 & 7.144 & 0.008 & $6.386(1.640-24.873)$ \\
Live alone & 1.615 & 14.732 & 0.000 & $5.026(2.204-11.463)$ \\
Smoking & 0.994 & 16.544 & 0.000 & $2.702(1.674-4.362)$ \\
Drink tea & -1.254 & 29.943 & 0.000 & $0.285(0.182-0.447)$ \\
Nap & -0.569 & 5.379 & 0.020 & $0.566(0.350-0.916)$ \\
Physical exercise & -0.091 & 0.155 & 0.694 & $0.913(0.58 I-1.435)$ \\
Social engagement & -1.928 & 64.496 & 0.000 & $0.145(0.091-0.233)$ \\
Hobbies & -0.865 & 13.227 & 0.000 & $0.421(0.264-0.671)$ \\
High-fat diet & 1.084 & 22.694 & 0.000 & $2.955(1.892-4.615)$ \\
\hline
\end{tabular}

high-fat diet $(7.519 \%$; 10 cases). Among the participants who had social engagement and a high-fat diet, the probability of MCI of those with hobbies was 35.211\% (25 cases), lower than that of those without hobbies (81.250\%; 39 cases). Among participants who had social engagement, a high-fat diet, and hobbies, the probability of MCI among people living alone was $77.778 \%$ (7 cases), higher than those living with their families (29.032\%; 18 cases). In addition, among the people who did not have social engagement, the probability of MCI among tea drinkers was 49.153\% (87 cases), lower than that of those who did not drink tea $(86.224 \% ; 169$ cases). Among those who had no social engagement and drank tea, the probability of MCI among those living with their families was $45.679 \%$ (74 cases), lower than that of participants living alone (86.667\%; 13 cases). Among the people who had no social engagement, drank tea, and lived with their families, the probability of MCI among smokers was $60 \%$ (36 cases), lower than that of non-smokers $(37.225 \% ; 38$ cases) (Figure 1$)$.

The Importance of Prediction Variables in the Decision Tree Model

The importance of each node prediction variable to the construction of the model was different in the decision tree model, while the importance of social engagement as the root node variable was $33.57 \%$. In the leaf nodes, the importance of a high-fat diet, tea drinking, hobbies, living conditions, and smoking were $27.74 \%, 22.14 \%, 11.94 \%$, $4.61 \%$, and $0 \%$, respectively (Figure 2 ).

\section{Prediction of ROC Curve of $\mathrm{MCl}$ Occurrence by Decision Tree Model}

Taking the prediction of the decision tree model as the test variable and the real $\mathrm{MCI}$ data as the state variable to draw the ROC curve, it was concluded that the AUC of the decision tree model for predicting the occurrence of MCI was 0.827 (95\% CI: 0.795 0.856), $P<0.001$. This shows that the prediction effect of the decision tree model was good (Figure 3).

\section{Discussion}

In this study, logistic regression analysis showed that low education, living alone, smoking, and a high-fat diet were risk factors for MCI, while a young age, tea drinking, afternoon naps, social engagement, and hobbies were protective factors for MCI. These results were basically consistent with previous studies. ${ }^{22-24}$ With social engagement, a high-fat diet, hobbies, living conditions, tea drinking, and smoking entering each node of the decision tree model, social engagement was the root node variable and the most important predictor of MCI. The probability of MCI in the elderly with social engagement was significantly lower than that in those without social engagement. The results of a large cross-border study involving 19,832 people over a period of six years showed that social engagement plays an important role in cognitive function and successful aging, but the relationship between social engagement and cognitive function is not yet clear. $^{25}$ The possible mechanism is that 


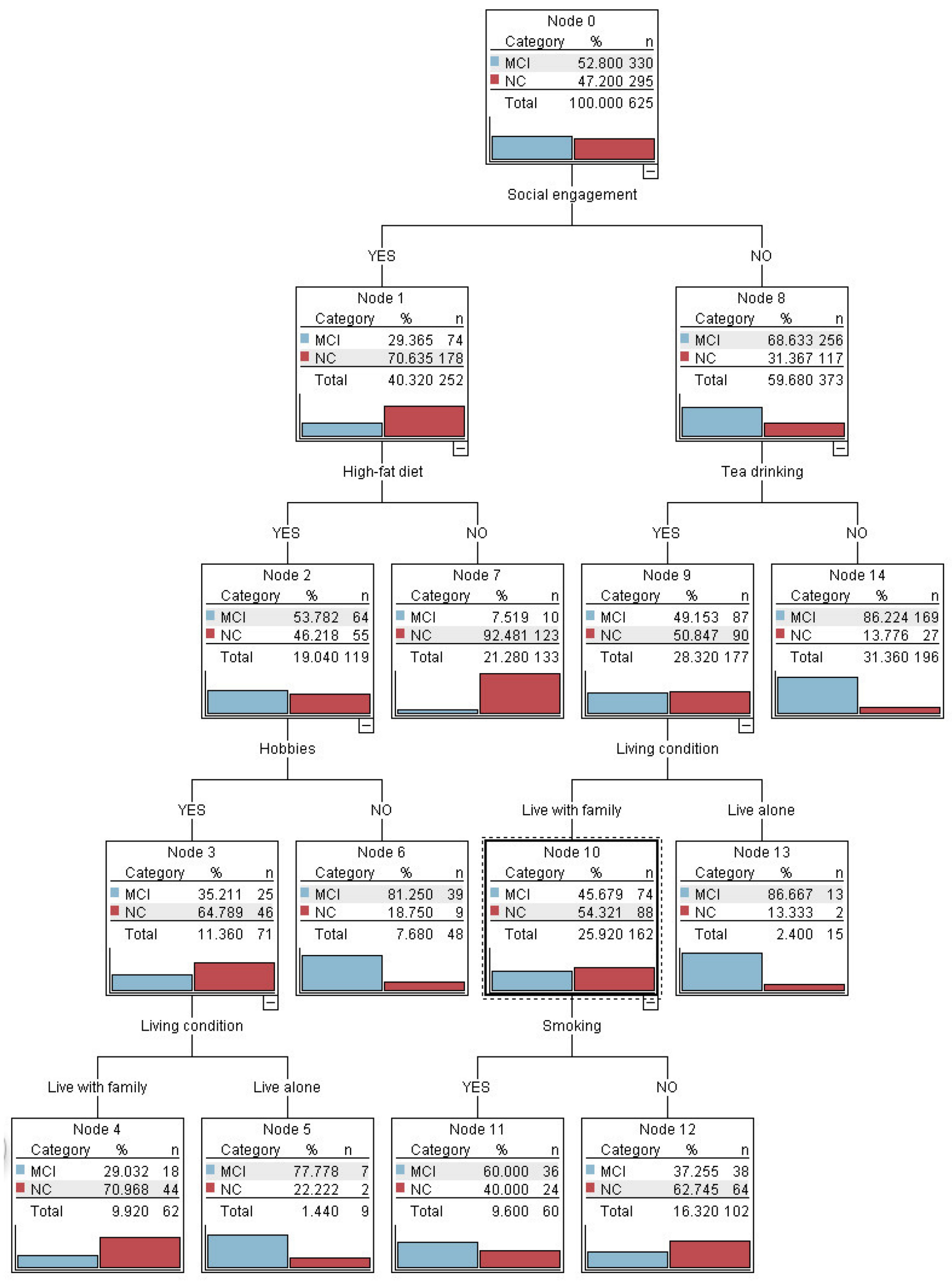

Figure I Decision tree model of the influence of lifestyles on $\mathrm{MCl}$. This tree is generated by the software through 10 cross-validations. Each box is numbered sequentially. The blue icon represents $\mathrm{MCl}$, and the red icon represents $\mathrm{NC}$. Each box has its own percentage and specific number of examples. Below each box is the influence factor of the next classification; at the top of each box is the corresponding category of influence factor.

Notes: $\mathrm{MCl}$ is mild cognitive impairment, $\mathrm{NC}$ is normal cognitive function. 


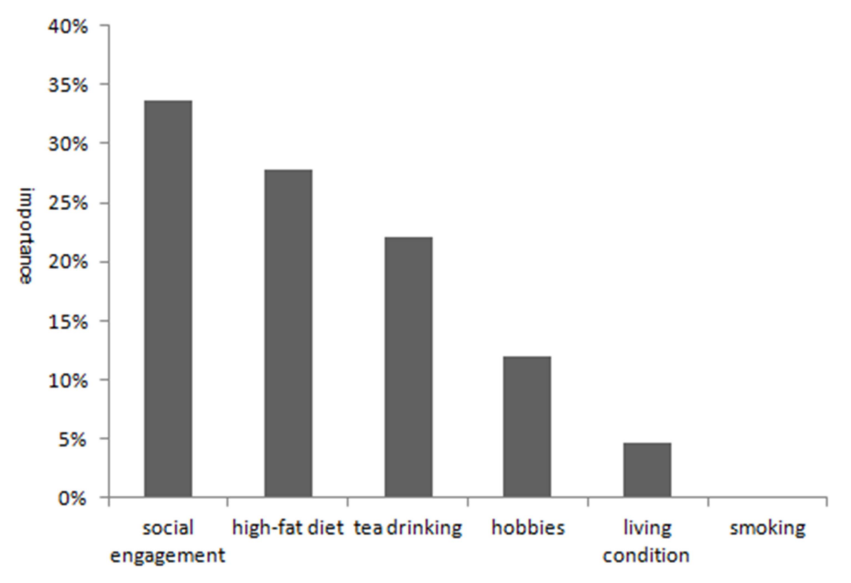

Figure 2 Importance of predictive variables in decision tree model. This figure shows the importance of each influence factor to the result prediction in the decision tree model. As a root node variable, social engagement is the most important predictive variable.

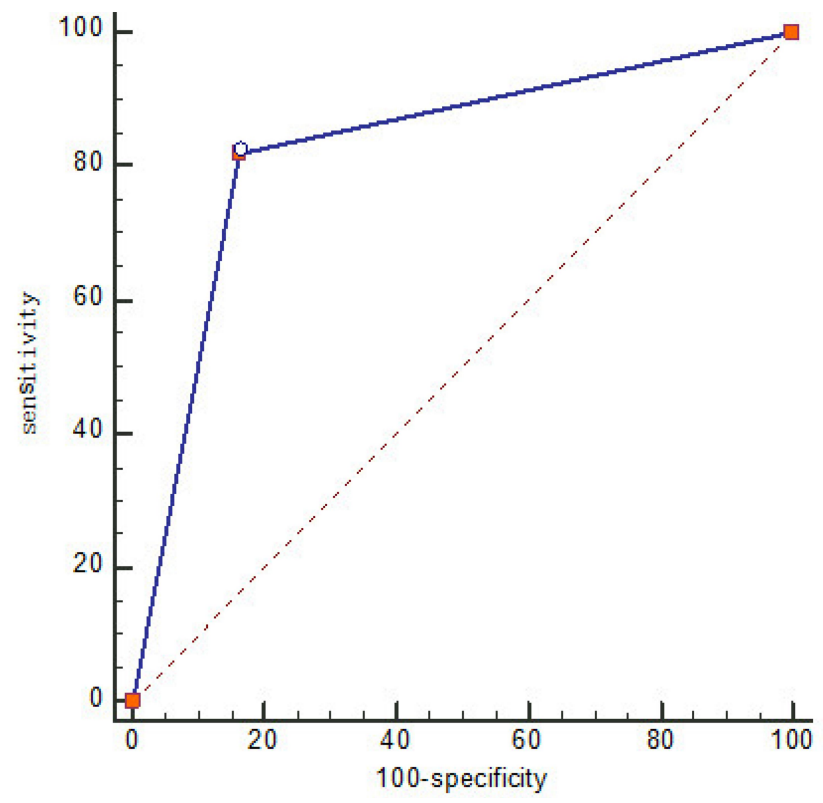

Figure $3 \mathrm{ROC}$ curve of $\mathrm{MCl}$ occurrence predicted by decision tree model. The broken line in the figure represents the ability of the decision tree model to predict the occurrence of $\mathrm{MCl}$. The AUC was $0.827, P<0.001$.

environmental complexity is an important factor in cognitive reserve; social engagement enables MCI patients to better compensate for brain changes, such as aging, cognitive impairment, and $\mathrm{AD}$ by activating and strengthening neurobiological pathways. ${ }^{26}$

In people who have social engagement, those who eat a high-fat diet have a high probability of developing MCI; this may be due to a high-fat diet leading to hypercholesterolemia, increased oxidative stress, and an increased concentration of the amyloid protein in the hippocampus, resulting in a decline in cognitive function. ${ }^{27}$ For example, a 30-year retrospective cohort study showed that middleaged hypercholesterolemia increases the risk of dementia in the elderly by $27 \% .{ }^{28}$ In people with social engagement and a high-fat diet, those with hobbies have a low probability of developing MCI, and studies have shown that hobbies (such as reading, music, and chess) can make related neural networks more effective or more malleable, thus delaying the onset of dementia and cognitive deterioration. ${ }^{29}$ A study of 6586 subjects followed up with over five years found that the risk of MCI in the elderly who read regularly decreased by $41 \%$, and the protective effect on the cognitive function of the welleducated elderly was more obvious. ${ }^{30}$ Among the participants with social engagement, a high-fat diet, and hobbies, those living alone had a high probability of MCI. Chinese scholars have shown that the low psychological elasticity of people living alone is an important factor leading to the occurrence and development of $\mathrm{MCI}{ }^{31}$

In the subjects without social engagement, tea drinkers have a low probability of developing MCI. Studies have shown that tea polyphenols can resist oxidative stress and protect nerve cells. ${ }^{32}$ Among participants who had no social engagement, drank tea, and lived with their families, smokers had a higher probability of developing MCI. A study in Rotterdam showed that smoking increased the risk of cognitive decline ( $\mathrm{OR}=1.47,95 \%$ CI: $1.18-1.86$ ) after an average of 7.1 years of follow-up in elderly smokers. ${ }^{33}$ A large number of toxic substances in cigarettes (such as carbon monoxide and nitrosamines) accumulate free radicals and damage nerve cells, resulting in cognitive decline. ${ }^{34}$

In the results of the decision tree model of this study, we also found that people with hobbies and non-high-fat diets have the lowest probability of MCI (7.519\%), while those who have no hobbies, drink tea, and live alone have the highest probability of MCI $(86.667 \%)$, which is similar to the probability of those with MCI who do not have hobbies and do not drink tea. It can be seen that the interaction of protective factors can minimise the incidence of MCI, while the interaction of risk factors can increase the probability of MCI.

Therefore, the decision tree model can intuitively and clearly show the influence and probability of each factor entering the model on MCI and can be read down along each main line, with a high degree of readability. The AUC of the ROC curve of MCI predicted by the decision tree model is 0.827 (95\% CI: $0.795 \sim 0.856)$. It is a good method to analyse the influencing factors of clinical 
disease and predict the probability of disease occurrence. The limitation of this study is that the lifestyle should be further refined, such as the time, intensity and type of physical exercise, the type of tea being consumed, and the frequency of alcohol consumption. In addition, more samples should be included to increase the reliability of the model.

\section{Conclusion}

This study shows that MCI is closely related to a variety of lifestyles, among which social communication is the most important factor to predict the occurrence of MCI. Other influencing factors such as high-fat diet, tea drinking, hobbies, and living condition also have a certain impact on the occurrence of MCI. The decision tree model method has a good ability to predict MCI, and the interaction between factors can have a further impact on the occurrence of MCI. Therefore, individual lifestyle intervention can be carried out for the elderly in order to reduce the incidence of MCI.

\section{Highlights}

We found that low education, living alone, smoking, and high-fat diet were risk factors for MCI, while low age, tea drinking, afternoon naps, social engagement, and hobbies were protective factors for MCI.

The decision tree model has good predictive ability, with social engagement as the most important factor in predicting the occurrence of MCI. Other factors such as a high-fat diet, tea drinking, hobbies, and living condition can also predict the occurrence of MCI.

The combination of medical research and data mining technology provides new ideas for future research.

\section{Funding}

This study was supported by the Shandong Science and Technology Development Plan Project (2011YD18045), Natural Science Foundation of Shandong Province (ZR2012HM049), Fund supported Project of Qingdao Science and Technology Bureau (09-1-1-33-nsh; 159-2-74-nsh), and Fund Project of Science and Technology Bureau of Huangdao District of Qingdao (2014-1-73).

\section{Disclosure}

The authors have no conflicts of interest regarding the content of this article.

\section{References}

1. Petersen RC, Smith GE, Waring SC, et al. Mild cognitive impairment: clinical characterization and outcome. Arch Neurol. 1999;56 (3):303-308. doi:10.1001/archneur.56.3.303

2. Peterson RC, Lepez O, Armstrong MJ, et al. Practice guideline update summary: mild cognitive impairment: report of the guideline development, dissemination, and implementation subcommittee of the American Academy of Neurology. Neurol. 2018;90(3):126-135. doi:10.1212/WNL.0000000000004826

3. Langa KM, Levine DA. The diagnosis and management of mild cognitive impairment: a clinical review. JAMA. 2014;312(23):25 51-2561. doi:10.1001/jama.2014.13806

4. Gonzalez HM, Tarraf W, Schneiderman N, et al. Prevalence and correlates of mild cognitive impairment among diverse Hispanics/Latinos: study of Latinos-investigation of neurocognitive aging results. Alzheimers Dement. 2019;15(12):1507-1515. doi:10.1016/j.jalz.2019.08.202

5. Kuhn M, Johnson K. Applied Predictive Modeling. Vol. 13. Nonlinear classification models; 2013:329-367.

6. Lemen SC, Roy J, Clark MA, Friedmann PD, Rakowski W. Classification and regression tree analysis in public health: methodological review and comparison with logistic regression. Ann Behav Med. 2003;26(3):172-181. doi:10.1207/S15324796ABM2603_02

7. Tufféry S. Data Mining and Statistics for Decision Making. 1 st ed. John Wiley \& Sons, Ltd; 2011.

8. Yong HH, Karmakar C, Borland R, Kusmaker S, Fuller-Tyszkiewicz M, Yearwood J. Identifying smoker subgroups with high versus low smoking cessation attempt probability: a decision tree analysis approach. Addict Behav. 2020;103:106258. doi:10.1016/j.addbeh.2019.106258

9. Li H, Wu TT, Yang DL, et al. Decision tree model for predicting in-hospital cardiac arrest among patients admitted with acute coronary syndrome. Clin Cardiol. 2019;42(11):1087-1093. doi:10.1002/clc.23255

10. Pei D, Zhang C, Quan Y, Guo Q. Identification of potential type II diabetes in a Chinese population with a sensitive decision tree approach. J Diabetes Res. 2019;2019:1-7. doi:10.1155/2019/4248218

11. Brims FJ, Meniawy TM, Duffus I, et al. A novel clinical prediction model for prognosis in malignant pleural mesothelioma using decision tree analysis. J Thorac Oncol. 2016;11(4):573-582. doi:10.1016/ j.jtho.2015.12.108

12. Wang X, Guo ZJ, Zhang WQ, et al. Study on the decision tree model for risk factors of vascular cognitive impairment. Chin J Behav Med Brain Sci. 2017;26(6):534-538.

13. Solfrizzi V, D'Introno A, Colacicco AM, et al. Lifestyle-related factors, alcohol consumption, and mild cognitive impairment. $J \mathrm{Am}$ Geriatr Soc. 2007;55(10):1679-1681. doi:10.1111/j.1532-5415.2007. 01313.x

14. Wingbermuhle R, Wen KX, Wolters FJ, Ikram MA, Bos D. Smoking, APOE genotype, and cognitive decline: the Rotterdam study. J Alzheimers D. 2017;57(4):1191-1195. doi:10.3233/JAD-170063

15. Falck RS, Davis JC, Best JR, Crockett RA, Liu-Ambrose T. Impact of exercise training on physical and cognitive function among older adults: a systematic review and meta-analysis. Neurobiol Aging. 2019;79:119-130. doi:10.1016/j.neurobiolaging.2019.03.007

16. Albert M, DeKosky S, Dickson D,etal. The diagnosis of mild cognitive impairment due to Alzheimer s disease:recommendations from the National Institute on Aging-Alzheimers association workgroups on diagnostic guidelines for Alzheimers Dement. 2011;7(3):270-279. doi:10.1016/j.jalz.2011.03.008

17. Hunter SW, Divine A, Frengopoulos C, Montero Odasso M. A framework for secondary cognitive and motor tasks in dual-task gait testing in people with mild cognitive impairment. BMC Geriatr. 2018;18(1):202. doi:10.1186/s12877-018-0894-0

18. Snitz BE, Wang T, Cloonan YK, et al. Risk of progression from subjective cognitive decline to mild cognitive impairment: the role of study setting. Alzheimers Dement. 2018;14(6):734-742. doi:10.1016/ j.jalz.2017.12.003 
19. Zhang ZX, Hong X, Li H, et al. The mini-mental state examination in the Chinese residents population aged 55 years and over in the urban and rural areas of Beijing. Chin J Neurol. 1999;32(3):149-153.

20. Morris JC. The Clinical Dementia Rating (CDR): current version and scoring rules. Neurol. 1993;43(11):2412-2414. doi:10.1212/WNL. 43.11.2412-a

21. Mahoney FI, Barthel DW. Functional evaluation: the barthel index. Md State Med J. 1965;14:61-65.

22. Su XN, Hua QZ, Zhang L, Li NN, Cheng JH, Zhang LP. Influencing factors of mild cognitive impairment of seniors in communities of Xi'an. J Nurs. 2013;11:10-13.

23. Fu C, Yang F, Mao ZF. Mild cognitive impairment and its influencing factors of empty nest elderly in social district of Wuhan. Chin J Gerontology. 2018;38(23):220-222.

24. Li X, Ma C, Zhang J, et al. Prevalence of and potential risk factors for mild cognitive impairment in community-dwelling residents of Beijing. $J \mathrm{Am}$ Geriatr Soc. 2013;61(12):2111-2119. doi:10.1111/jgs.12552

25. Bourassa KJ, Memel M, Woolverton C, Sbarra DA. Social participation predicts cognitive functioning in aging adults over time: comparisons with physical health, depression, and physical activity. Aging Ment Health. 2017;21(2):133-146. doi:10.1080/13607863.2015.1081152

26. Stern Y, Barulli D. Cognitive reserve. Neuropsychologia. 2009;47 (10):2015-2028. doi:10.1016/j.neuropsychologia.2009.03.004

27. Gamba P, Testa G, Gargiulo S, et al. Oxidized cholesterol as the driving force behind the development of alzheimer's disease. Front Aging Neurosci. 2015;7:119. doi:10.3389/fnagi.2015.00119

28. Whitmer RA, Sidney S, Selby J, Johnston SC, Yaffe K. Midlife cardiovascular risk factors and risk of dementia in late life. Neurology. 2005;64 (2):277-281. doi:10.1212/01.WNL.0000149519.47454.F2
29. Stern Y. Cognitive reserve in ageing and alzheimer's disease. Lancet Neurol. 2012;11(11):1006-1012. doi:10.1016/S1474-4422 (12)70191-6

30. Zhu XY, Qiu CX, Zeng Y, Li J. Leisure activities, education, and cognitive impairment in Chinese older adults: a population-based longitudinal study. Int Psychogeriatr. 2017;29(5):727-739. doi:10.10 17/S1041610216001769

31. Xie LQ, Deng YL, Tang Y, Zhou J. The status quo of resilience in empty-nest elderly with mild cognitive impairment in the rural area and path analysis on the influencing factors. Chin J Behav Med Brain Sci. 2015;24(1):66-68.

32. Qi GY, Mi YS, Wang YW, et al. Neuroprotective action of tea polyphenols on oxidative stress-induced apoptosis through the activation of the TrkB/CREB/BDNF pathway and Keap1/Nrf2 signaling pathway in SH-SY5Y cells and mice brain. Food Funct. 2017;8 (12):4421-4432. doi:10.1039/C7FO00991G

33. Reitz C, den Heijer T, van Dujin C, Hofman A, Breteler MM. Relation between smoking and risk of dementia and alzheimer disease: the Rotterdam Study. Neurol. 2007;69(10):998-1005. doi:10.1212/01.wnl.0000271395.29695.9a

34. Lobo V, Patil A, Phatak A, Chandra N. Free radicals, antioxidants and functional foods: impact on human health. Phcog Rev. 2010;4 (8):118-126. doi:10.4103/0973-7847.70902
Clinical Interventions in Aging

\section{Publish your work in this journal}

Clinical Interventions in Aging is an international, peer-reviewed journal focusing on evidence-based reports on the value or lack thereof of treatments intended to prevent or delay the onset of maladaptive correlates of aging in human beings. This journal is indexed on PubMed Central, MedLine, CAS, Scopus and the Elsevier
Dovepress

Bibliographic databases. The manuscript management system is completely online and includes a very quick and fair peer-review system, which is all easy to use. Visit http://www.dovepress.com/ testimonials.php to read real quotes from published authors. 